\title{
Electric car chassis design and analysis by using CATIA V5 R19
}

\author{
Ahmad Zainal Taufik ${ }^{1}$, Nur Rashid ${ }^{1}$, Mazlan $^{1}$, Mohd Faruq ${ }^{1}$, \\ Muhammad Zahir ${ }^{1}$ \\ ${ }^{1}$ Universiti Teknikal Malaysia Melaka, Malaysia
}

\begin{abstract}
The evolution of computer aided design (CAD) systems and related technologies has promoted the development of software for the east of chassis modeling. It visualizes the main outputs of the model, which consist in numeric data and graphic elements. This reduces the simulation time dramatically and enables the optimization process to come to successful results. This paper presents an electric car chassis design by using the commercial design software package, CATIA V5 R19. The design of the chassis with adequate stiffness and strength is the aim of this project. The material used is mild steel AISI 1018 with $386 \mathrm{MPa}$ of yield strength and 634 MPa of ultimate strength. The result shows that the critical point of stress and displacement occurred in the middle of the side members in all loading conditions, maximum stresses are below the yield stress. The final products for the design have been fabricated successfully.
\end{abstract}

Keywords: Electric car, chassis design, CATIA V5 R19, Stress analysis, load analysis

\section{Introduction}

Technical innovations in vehicle design, will play a very considerable role in the future in reducing emissions. Electric drive vehicles are becoming an attractive alternative to combustion engine cars with global gradual fossil fuel prices rise. In addition, increasing energy prices also have led to an increase interest in the development of electric vehicles. In the European Union, the car manufacturers have agreed to an overall $25 \%$ increase in fuel efficiency by the year 2005 compared to 1990 [1]. In addition, concerns over climate change and reduction of greenhouse gas emissions, and dependence of economies on foreign energy sources, have also become an initiative for extensive research on the use of electric cars as an alternative [2, 3, 4]. Quality has been one of the key issues for the automotive industry. The breakdown of Initial Quality Survey 1997 by [5] indicates that the problems related to body and dimensional quality count for up to $41 \%$ percent of the total problems. Cars with electrical drive systems represent a solution for the future, and will in a steadily increasing degree be seen on the roads. The history of electric cars is closely related to the history of batteries $[6,7,8]$. Electric cars appear to be the most suitable candidates to fulfill the environmental demands.

In electric cars, efficiency of energy usage is very important. In order for an electric car to perform at its best it must have adequate structure, this means it must have a stiff frame. Since most of the car's weight is between the front and rear suspension, frame stiffness is absolutely the key between these points where it will not easily bend. For the electric car, stiffness is very important. Apart from safety requirements the chassis structure in itself should also provide torsional and bending stiffness as well as direct support for the front suspension and steering system mounting points. Some value of the safety factor for various condition of loading and material of structures was recommended by Vidosic [9]. Two aspects of frame stiffness should be considered which are beaming and torsional. Therefore the chassis is considered as the most important element of the vehicle as it holds all the parts and components together.

The chassis is the "skeleton" of the car which providing the structural strength, and the mounting points for other components. The chassis provides necessary support to the vehicle components placed on it such as suspension components and the weight of the driver. Electric car chassis designing and fabrication involves tradeoffs. There is no one ideal design. One obvious consideration is that the car must not be too heavy. This will make it easier for the motor to push a lighter car than a big, heavy one. Chassis systems determine many of the vehicle fundamentals behavior and "character", in particular ride comfort and (to a considerable degree) noise levels on one hand, and the quality of steering, handling and road holding on the other. The best design of the chassis is a matter of finding a compromise between performances, safety and manufacturing costs. Beside safety aspects, the chassis must also be designed with fuel efficiency in mind. Chassis design will be optimized to accommodate both the safety and fuel efficiency requirements. Many researchers had conducted an analysis on chassis of various vehicles by using finite element method [10, 11]. Modern lightweight design techniques are one of the key technologies in the development of efficient and sustainable mobility solutions.

In this study, an attempt is made to design an electric car chassis that would reduce the weight and able to provide high specific strength and high specific stiffness, and easy to be manufactured. A monocoque chassis design was selected. Figures I show the computational model of monocoque design. Previous researches have shown that the efficient design and the use of different materials in the automotive parts directly influences the 
car safety, weight reduction and gas emission, because the efficient design can absorb more deformation and provide high specific strength and high specific stiffness [12]). Increasing legal and market demands for safety, the weight of the car body will most likely increase in the future.

\section{Experimental set up}

The commercial design software package, CATIA V5 R19 is used for the design and analysis of the chassis. The chassis frame is modelled with 3D-dimensional. The chassis was modelled as beam elements with circular hollow sections. The circular hollow section has a diameter of $32 \mathrm{~mm}$ and thickness of $1.5 \mathrm{~mm}$. About 650 linear beam elements were used for the chassis. Material properties were assigned to the model. Load value was varied from $700 \mathrm{~N}$ to $1500 \mathrm{~N}$ and the results of FEA i.e. maximum stress and deflection were then compared to the analytical value.

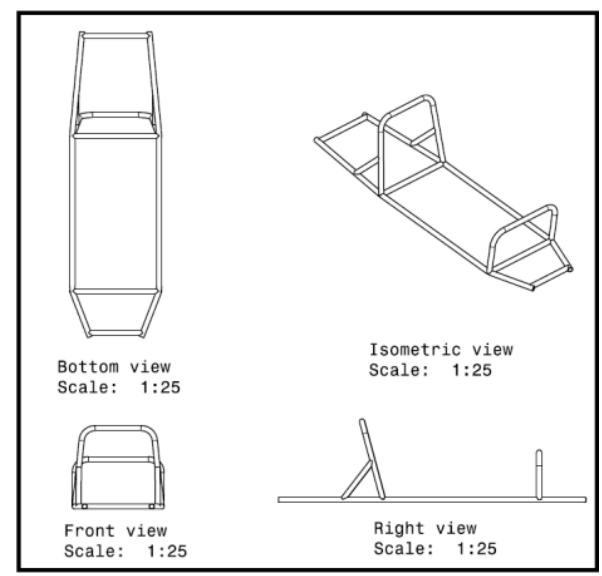

Figure 1: The develop chassis design concept

\section{Material Selection}

The raw material for the chassis structure is mild steel AISI 1018. The property of the material is presented in Tables 1 and 2.

Table 1: Mechanical Properties of AISI 1018 steel

\begin{tabular}{|l|c|}
\hline Density $\left(\mathrm{x} 1000 \mathrm{~kg} / \mathrm{m}^{3}\right)$ & $7.7-8.03$ \\
\hline Poisson Ratio & $0.27-0.30$ \\
\hline Elastic Modulus $(\mathrm{GPa})$ & $190-210$ \\
\hline Tensile strength $(\mathrm{Mpa})$ & 634 \\
\hline Yield Strength $(\mathrm{Mpa})$ & 386 \\
\hline Elongation (\%) & 27 \\
\hline Reduction in Area (\%) & 48 \\
\hline Hardness (HB) & 197 \\
\hline
\end{tabular}

Table 2: Chemical Properties of AISI 1018

\begin{tabular}{|c|c|}
\hline Element & Weight \% \\
\hline $\mathrm{C}$ & $0.15-0.20$ \\
\hline $\mathrm{Mn}$ & $0.60-0.90$ \\
\hline $\mathrm{P}$ & $0.04(\max )$ \\
\hline $\mathrm{S}$ & $0.05(\max )$ \\
\hline
\end{tabular}

\section{Finite Element Analysis}

The chassis was first designed in CATIA software. The CATIA CAD model, then exported into the FEA software. The chassis was modelled as beam elements with circular hollow sections. A static analysis performed on the chassis frame as it is an effective and efficient approach. The analysis was performed based on following assumptions:-

- The maximum design of payload for the chassis structure during application is approximately $1.5 \mathrm{kN}$.

- The total load is distributed over the contact surface on chassis structure.

The chassis was simulated with nine different loading condition starts from $700 \mathrm{~N}$ to $1500 \mathrm{~N}$. A safety factor of 1.5 is used to take into account the uncertainties of actual loading and fabrication inconsistencies that may reduce the strength of the chassis. Simply supported constraints will be on the front and rear wheelbase points. The model has been meshed as the octree tetrahedron mesh. The size of each element is set to $3 \mathrm{~mm}$. 
The element type is linear. Boundary conditions for the model were four areas of fixed point applied to model (Fig.2). In this study, the load used is a static type and the thickness of the tube was kept constant.

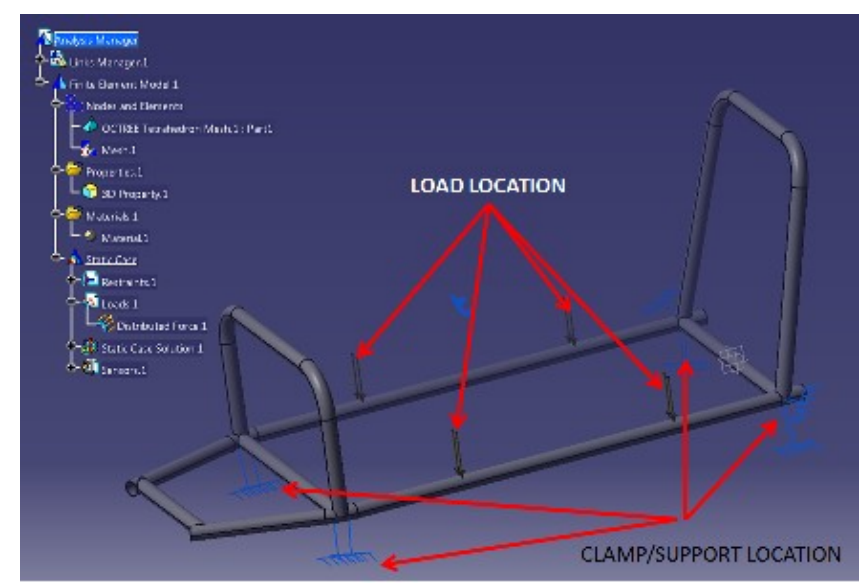

Figure 2: Load applied location

\section{Results}

Fig. 3 illustrates the example results of the simulation analysis of loading test. Loads acting in the plane of the frame caused bending of the side members. The deflection of $0.098 \mathrm{~mm}$ starts to occur at $700 \mathrm{~N}$ load. The deflection increased with increased load. The most severe chassis deflections occurred at the center of the side members where the driver seat is mounted. According to Heisler and Heinz [14], depending upon the application of loads and their direction, chassis is deformed in a respective manner such as longitudinal torsion, vertical bending, lateral bending, and horizontal lozenging. From the analysis it was observed that this design and material able to withstand the engine and driver load with a minimum displacement. This shows that, the chassis frame design is suitable and be ready for manufactured.

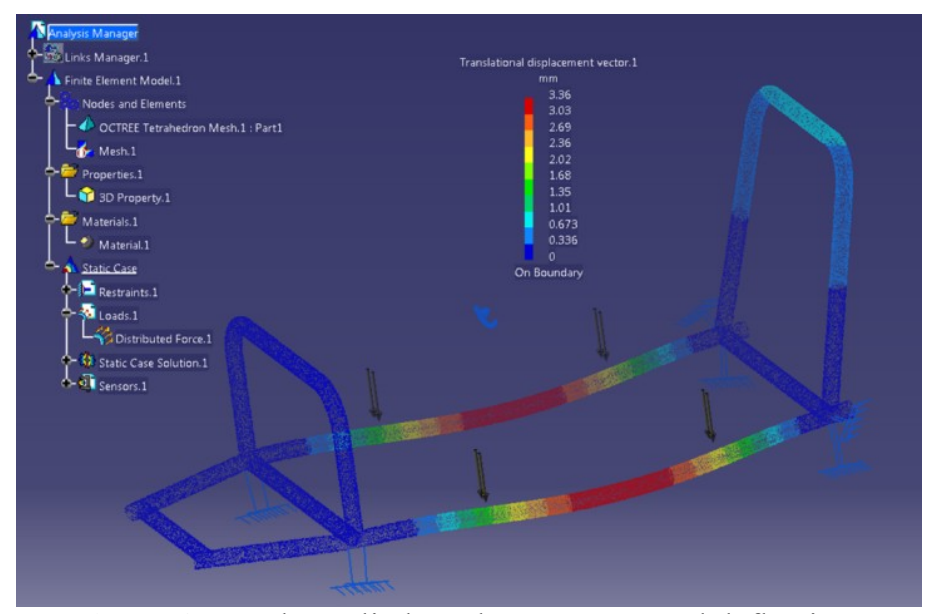

Figure 3: Loads applied produce stresses and deflections

From the results it is also found that the critical point of Von Misses stress is located at the center of the side members. When the load of the side member is increased from $700 \mathrm{~N}$ to $1500 \mathrm{~N}$ the Von-Mises stress on the side members are also increasing. In this case, the overall stress on the chassis frame increases considerably with increase in load. Fig. 4 shows the Von-Mises stress values along the side members for $1.5 \mathrm{kN}$ load. 


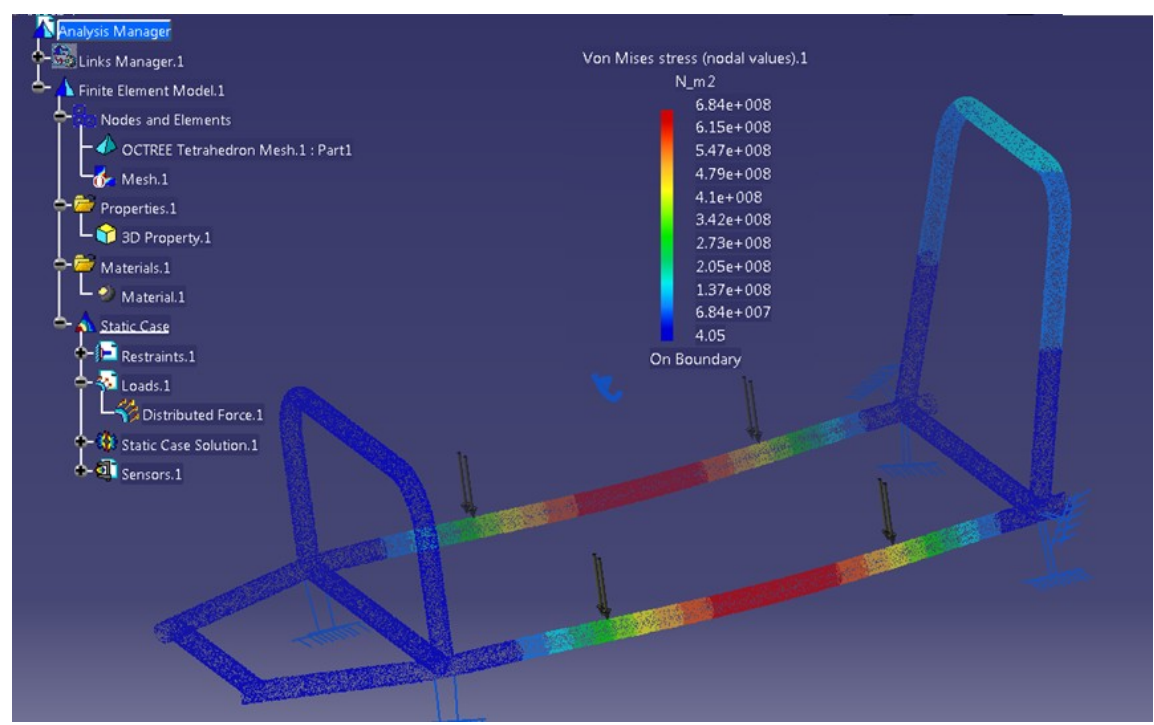

Figure 4: The Von-Mises stress distribution for a side members

\section{Conclusion}

The development and application of the finite element analysis considerably reduce the chassis design process. The chassis was designed so as the vehicle can withstand the loads with a specific strength. The simulation analysis results have established approving outcome in term of Von-Mises stress values and deflections for different loading tests. In most loading conditions, maximum stresses are below the yield stress. The final products for the designs have been fabricated successfully.

\section{Acknowledgements}

The authors gratefully acknowledged the financial support from Universiti Teknikal Malaysia Melaka under short term grant: PJP/2012/FTK(4C)/S01005.

\section{References}

[1]. G.L. Farely, Energy absorption of composite materials, Journal of Composite Materials, 17, 1983, $267-279$.

[2]. Laurencas Raslavičius, Martynas Starevičius, Artūras Keršys, Kęstutis Pilkauskas, Andrius Vilkauskas Rastislav Rajnoha, Martin Jankovský, Martina Merková, Economic comparison of automobiles with electric and with combustion engines: An analytical study, Procedia - Social and Behavioral Sciences, 109, 2014, 225 - 230.

[3]. J.M. Miller, A. Emadi, A.V. Rajarathnam, M. Ehsani, Current status and future trends in More Electric Car power systems, Proc. $49^{\text {th }}$ IEEE Conf. on Vehicular Technology, Houston, TX, 1999, $1380-1384(2)$.

[4]. Hugo Morais, Tiago Sousa, Zita Vale, Pedro Faria, Evaluation of the electric vehicle impact in the power demand curve in a smart grid environment, Original Research Article Energy Conversion and Management, 82, 2014, 268-282.

[5]. J. D. Power and Associates, 1997. "Initial Quality Survey 1997 for Automobiles". J.D. Power and Associates, May.

[6]. D. Sperling, Future Drive (Island Press, Washington, DC, USA, 1995).

[7]. M.H. Westbrook, The electric car: Development and future of battery, Hybrid and fuel-cell cars, Society of Automotive Engineers Inc., Warrendale, PA, USA. 2001

[8]. J. Anderson, C.D. Anderson, . Electric and Hybrid Cars: A History (London, UK., McFarland \& Co., 2005)

[9]. J.P. Vidosic, Machine Design Project (New York, Ronald Press, 1957).

[10]. Pooja Doke, Mohammad Fard, Reza Jazar, Vehicle concept modeling: A new technology for structures weight reduction, Procedia Engineering, 49, 2012, $287-293$.

[11]. Roslan Abd Rahman, Mohd Nasir Tamin, Ojo Kurdi, stress analysis of heavy duty truck chassis as a preliminary data for its fatigue life prediction using FEM, Jurnal Mekanikal, December 2008, No. 26, 76 - 85

[12]. Zhanbiao Li, Development and Analysis of A Prototype Car-Carrier Structure Using the Finite Element Method, Thesis, Degree of Master of Applied Science, at the University of Windsor, Windsor, Ontario, Canada, 2003

[13]. W.B. Riley, A.R. George, Design, Analysis and Testing of Formula SAE Race Car Chassis, SAE paper 2002-01-3300, Motorsports Engineering Conference and proceedings, 2002

[14]. Heisler, Heinz, “Advanced Vehicle Technology", Edward Arnold, 1989 